\title{
Racismo de Estado e tanatopolítica: reflexões sobre os jovens e a lei
}

\author{
Andrea Cristina Coelho Scisleski, „ Jhon Lennon Caldeira da Silva, Giovana Barbieri Galeano, \\ Bruna Soares Bruno, Suyanne Nayara dos Santos \\ Universidade Católica Dom Bosco, Campo Grande, MS, Brasil
}

\begin{abstract}
Resumo
O presente artigo busca discutir, a partir de pesquisa realizada no contexto de Campo Grande/Brasil, as políticas públicas dirigidas a jovens em conflito com a lei, tomando como operadores de análise os conceitos de racismo de Estado e de tanatopolítica, a partir do referencial teórico de Michel Foucault e de Giorgio Agamben, respectivamente. O texto discute como as politicas públicas vêm sendo destinadas a esses jovens, tanto pelas práticas que as implementam quanto pelas suas falhas e não cumprimento, vezes em que abandonam e desprotegem essa população. O debate centra-se em uma reflexão sobre a condição em que os jovens se encontram a partir de ações jurídico-políticas que os inserem em termos de vivência pela exclusão social. As reflexões finais do estudo apontam para uma forma de gestão não apenas da vida, mas também da morte desses jovens, que os mantém em uma situação de marginalidade, porém tutelada pelo Estado.
\end{abstract}

Palavras-chave: políticas públicas; jovens em conflito com a lei; racismo de Estado; tanatopolítica.

\section{Racism State and tanathopolitics: reflections on the youth and the law}

\begin{abstract}
This article presents a study on public policies directed at young people in conflict with the law, from a research in the context of Campo Grande/MS/Brazil, taking as operators of analysis the concepts of state racism and tanatopolitica, from the Michel Foucault's and Giorgio Agamben's theories, respectively. This paper discusses how public policies have been aimed at these young people, by practices that implement these policies and also by their failures, when they expose this population out from the legal protection. The debate concerns a reflexion on the condition the youth are faced by legal and political actions that usually frame them in terms of experiencing social exclusion. Finally, this study indicates a way of managing not only the life, but also the death of these young people, which keeps them in a situation of marginality warded by the state.
\end{abstract}

Keywords: public policies; youth in conflict with the law; state racism; thanatopolitics.

\section{Introdução}

A pesquisa que origina a escrita deste artigo parte da problematização do campo das políticas públicas dirigidas a jovens em conflito com a lei em medida socioeducativa de internação no contexto de Campo Grande/ Brasil. O objetivo deste texto é colocar em questão a relação dessas políticas com o conceito de racismo de Estado de Foucault (2005) e com o de tanatopolítica de Agamben (2007), evidenciando os pontos de convergência e divergência entre ambos os autores e levando em conta, sobretudo, como essas ideias se fazem presentes a partir do contexto de uma Unidade Educacional de Internação (UNEI). No decorrer desta escrita, optamos por fazer uma ligação entre as explanações desses filósofos e nossas reflexões, oriundas especialmente de três momentos do fazer da pesquisa: visita a uma UNEI, acompanhamento das audiências dos jovens, análise dos processos judiciais e produção de um diário de campo.

Em termos metodológicos, esse conjunto de operações (visita, audiências, processos e diário) foi tomado como uma estratégia para analisar como os jovens em conflito com a lei recebem atendimento, na modalidade da medida socioeducativa de internação, na relação entre práticas sanitárias e penais. Dessa forma, apesar de termos visitados todas as unidades educacionais de internação do município de Campo Grande/MS, a discussão aqui de-

\footnotetext{
^ Endereço para correspondência: Universidade Católica Dom Bosco, PPG Psicologia. Av. Tamandaré 6000 - Jardim Seminário. CEP: 79117-900 Campo Grande, MS - Brasil.E-mail: ascisleski@yahoo.com.br, jhoncal deira@hotmail.com, giovanagaleano@hotmail.com, brunasoares_bruno@hotmail.com, suy_11_@hotmail.com
}

senvolvida volta-se especificamente para uma unidade de internação que recebe os jovens do sexo masculino para cumprimento da medida socioeducativa no município em questão. Outrossim, as atividades de assistir audiências e de analisar os processos judiciais colocaram-se como ações que vislumbravam perceber como o jovem, que recebe a medida socioeducativa de internação, percorre o judiciário, a partir daquilo que profissionais da saúde e do jurídico delineiam como encaminhamento e justificativa à interdição de sua liberdade. Para tanto, na frequência de uma vez por semana por um período de três meses consecutivos, acompanhamos audiências e analisamos os processos dos jovens das respectivas audiências assistidas. Com o intuito de registrar aquilo que foi encontrado nessas atividades, bem como as nossas impressões e percepções do que ocorreu nas mesmas, compusemos um diário de campo (LIMA; MIOTO; PRA, 2007) que, semanalmente, foi discutido por nós. De modo breve, podemos dizer que este diário foi escrito individualmente por cada um dos pesquisadores envolvidos logo após a realização das atividades e debatido no grupo de pesquisa posteriormente. Cabe ainda mencionar que a UNEI visitada encontra-se atualmente em funcionamento, apesar de ter sido solicitada a sua interdição, como denunciado pelo Relatório da Ordem dos Advogados do Brasil desse estado (MATO GROSSO DO SUL, 2014), devido às condições precárias de atendimento e das instalações oferecidas ao jovem, violando as diretrizes do próprio Estatuto da Criança e do Adolescente (BRASIL, 1990). 
Diante desse cenário de pesquisa, entendemos como crucial destacar já de início o nosso posicionamento em prol da articulação entre as políticas públicas e a Psicologia, enfatizando as palavras de Coimbra e Nascimento (2001, p. 247) no que se refere à forma como Psicologia e política devem ser entendidas: “[...] como territórios que se cruzam, que se atravessam, que se complementam, que são múltiplos e impossíveis de serem apreendidos em sua totalidade". Dessa maneira, este artigo parte de uma perspectiva que poderá causar estranhamento àqueles acostumados com a Psicologia como campo restrito ao estudo do suposto "mundo interno" e individual dos sujeitos, mas "hoje é impossível para nós separar o que é psicológico do que é político; negamos suas essências, apostamos na constituição histórica desses campos de conhecimento e nas articulações que se operam entre eles" (COIMBRA; NASCIMENTO, 2001, p. 248). Dessa maneira, este texto também toca uma reflexão necessária sobre a Psicologia no cenário do debate sobre a redução da maioridade penal no Brasil.

\section{Algumas articulações possíveis: o pensamento de Foucault e a UNEI}

Como os principais conceitos operadores para a análise de nossa pesquisa corresponde ao racismo de Estado (FOUCAULT, 2005) e à tanatopolítica (AGAMBEN, 2007), começamos trazendo a anátomo-política do corpo humano, também chamada por Foucault (1988) de disciplina, que pode ser entendida como uma multiplicidade de técnicas que se instalam e ganham força a partir do final do século XVII e decorrer do século XVIII. Essa tecnologia tem como objeto o corpo, para individualizá-lo na busca de uma "normalização", através do treino, do aperfeiçoamento, da vigilância permanente, dos esquemas de hierarquia e obediência e, por vezes, do uso do castigo e do esquadrinhamento dos espaços, tendo por finalidade a docilização dos homens para maximizar suas forças com o mínimo de custo (FOUCAULT, 1988).

Em nossa visita a uma UNEI, pudemos analisar a importância da tecnologia disciplinar naquela instituição, já que a própria medida de internação incide sobre os corpos dos jovens, moldando-os por meio de diversos dispositivos: em um ambiente fechado, o jovem tem horários para dormir, acordar, receber visitas, tomar sol, organizar-se em fila, etc. Além disso, a modulação dos corpos pela disciplina é calculada e gerida a partir de saberes técnicos, como é o caso das prescrições emitidas pelos juízes, inspetores, médicos, psicólogos e assistente social, entre outros. Nesse aspecto, cabe ressaltar que o Sistema Nacional de Atendimento Socioeducativo (SINASE) tem a disciplina como uma de suas diretrizes pedagógicas no âmbito do atendimento socioeducativo, entendendo-a como um instrumento ressocializador: "a disciplina deve ser considerada como instrumento norteador do sucesso pedagógico, tornando o ambiente socioeducativo um pólo irradiador de cultura e conhecimento e não ser vista apenas como um instrumento de manutenção da ordem institucional" (BRASIL, 2006, p. 48).

Fractal, Rev. Psicol., v. 28 - n. 1, p. 84-93, 2016
Apesar de o entendimento do SINASE (BRASIL, 2006) colocar a disciplina no grau de instrumento capaz de tornar as UNEIs um ambiente socioeducativo, o que é vislumbrado na prática concerne à tomada dessa tecnologia como um método de coerção contra os jovens internados, o que efetivamente se mostra incapaz de socioeducá-los. O texto do SINASE (BRASIL, 2006) abre, ainda, a possibilidade de elaborarmos algumas questões, a saber: como a disciplina pode tornar-se um instrumento norteador do sucesso pedagógico? É possível socioeducar um sujeito por meio da internação? Será que tais diretrizes foram escritas com a finalidade de serem realmente implementadas? Nesse aspecto, nos parece que a disciplina como técnica aqui em questão atua como um operador do racismo de Estado (FOUCAULT, 2005), como apresentaremos a seguir.

A partir da reflexão sobre nossa ida à unidade socioeducativa, percebemos que a disciplina aplicada nos locais de internação se constitui como um importante fator de geração de conflito entre os jovens e os profissionais dessas instituições. Ainda durante a visita à UNEI, presenciamos um momento em que os jovens pediram que um funcionário abrisse a cela onde eles estavam detidos; em resposta, o inspetor alegou que não abriria, pois o horário estava "próximo ao lanche" e por isso iriam "permanecer trancados". A justificativa de que o horário estava "próximo ao lanche" parece-nos apenas uma forma disciplinar de facilitar a dinâmica institucional, não levando em conta as reais necessidades dos jovens que cumprem medidas socioeducativas. Devemos lembrar que não são incomuns os motins em unidades de internação, tendo como estopim a aplicação da disciplina, que por vezes se "confunde" com castigo.

Mas será possível falar em disciplina sem castigo no contexto desses jovens? Talvez a péssima situação dos ambientes de internação, geralmente insalubres, e o modo de aplicação da disciplina estão constituindo uma espécie de punição que excedem à própria lei, pois "as disciplinas estabelecem uma 'infra-penalidade'; quadriculam um espaço deixado vazio pelas leis; qualificam e reprimem um conjunto de comportamentos que escapava aos grandes sistemas de castigo por sua relativa indiferença" (FOUCAULT, 1999, p. 202).

Nesse sentido, tais "penalidades disciplinares" são sacramentadas pela opinião pública, que acredita que quanto mais rígido, controlado e desconfortável for o local de internação - ou seja, quanto mais disciplinado e punitivo -, menos o sujeito se sentirá tentado a reincidir no crime ou no ato infracional. Tal pensamento busca atribuir ao sujeito apenas a responsabilidade de decidir entre respeitar ou infringir a lei, não levando em consideração a necessidade de subsistência, nem se tal sujeito teve condições para desenvolver efetivamente possibilidades que pudessem oferecer opções que lhe permitissem atuar na sociedade não como marginalizado, mas como cidadão empenhado na produção de uma sociedade mais justa.

Ainda na ocasião da nossa visita, ao entrevistarmos o inspetor, este relatou que existe pouco ou nenhum investimento na qualificação de pessoal e que faz alguns 
anos que o Estado não realiza concursos públicos para a contratação de novos funcionários. Em tom de desabafo, disse que, "para ser bem sincero com vocês, quem trabalha aqui encara este trabalho como provisório, buscando passar num concurso melhor" (sic). Com essa situação precária, percebe-se que os profissionais das UNEIs ficam sobrecarregados e que alguns estão lá não porque realmente querem, encarando o trabalho como um momento de transição para um emprego melhor.

Através desse relato, percebe-se que a ausência de investimentos na qualificação e nas condições de trabalho acabam por contribuir com a desvirtuação na aplicação real de medidas que visam ao melhoramento no atendimento socioeducativo. É possível dizer que está vigorando a ideia de que, quanto pior a "socioeducação", melhor é para o Estado e para a sociedade? Ou que não se deve investir nesse segmento da população? Essas questões tornam-se pertinentes, pois vemos que muitos jovens reincidem em atos infracionais e retornam para internação (MATO GROSSO DO SUL, 2012). Inicia-se, desse modo, um ciclo até que o jovem tenha idade para ser preso como adulto ou mesmo morra em decorrência do ambiente violento no qual se insere (WAISELFISZ, 2011; SCISLESKI, 2010; REIS, 2012).

Ressaltamos que a reincidência dos jovens é o argumento principal para aqueles que defendem a redução da maioridade penal (BRASIL, 2012). Tal argumento perderia validade caso as medidas socioeducativas fossem efetivamente dispositivos socioeducativos e o Estatuto da Criança e do Adolescente (ECA) fosse largamente implementado. Sendo assim, a disciplina em questão, pelo menos no que diz respeito à prática, está longe da imaginada pelo SINASE (BRASIL, 2006) como instrumento pedagógico e facilitador do processo de ressocialização dos jovens em conflito com a lei. Entretanto, parece-nos que essa tecnologia disciplinar se assemelha à evidenciada por Foucault (1999) em Vigiar e Punir, onde o autor expõe a disciplina institucional como "a penalidade perpétua que atravessa todos os pontos e controla todos os instantes das instituições disciplinares: compara, diferencia, hierarquiza, homogeneíza, exclui. Em uma palavra, ela normaliza" (FOUCAULT, 1999, p. 207).

Nos processos a que tivemos acesso, especialmente aqueles relativos à internação provisória, encontramos pareceres que são emitidos para auxiliar o juiz a decidir se prorroga a medida de internação ou se coloca o jovem em liberdade. Chama a atenção, contudo, nesses pareceres a frequência de outro uso do termo "disciplina", desta vez relacionado ao comportamento dos jovens. É interessante notar como o tópico denominado de "disciplina" era respondido: em menos de quatro linhas. Nessas poucas linhas, evidenciava-se, a nosso ver, no entanto, mais a própria capacidade criada pelos técnicos do Estado de resumir um sujeito a meras expressões de seu comportamento do que a produção de informações importantes sobre a situação desses jovens. Ao mesmo tempo, há também, por parte do judiciário, uma demanda por diagnósticos e produções lacônicas de pareceres (CUNHA, 2000). A questão que pesa é que, independentemente da extensão, as informações que constam nos pareceres são tomadas como emissoras de "verdades" sobre os jovens. É através desses laudos que se saberá o impacto da adequação das medidas aos sujeitos a que se destinam: se eles possuem bom ou mau comportamento, se respeitam ou desrespeitam as normas disciplinares da unidade, se estão adaptados ou não às regras institucionais e até se são organizados ou desorganizados; enfim, esses discursos seguem operando na velha dicotomia "normal versus patológico" - o modo de categorizar os sujeitos em nossa sociedade.

Vale ressaltar, ainda, que o que impera nesses relatos técnicos é a questão da adaptação dos jovens ao ambiente da unidade; caso não estejam adaptados, é possível ao magistrado prorrogar a internação. Isso nos faz pensar sobre a capacidade de as instituições de internação culpabilizarem o sujeito, pois, se ele não se adapta à medida socioeducativa, a "pena" deve ser aumentada.

Outra questão não menos relevante é a de que a vida fora da instituição não segue, no seu cotidiano, grande parte das regras que existem dentro da instituição, como, por exemplo: jantar às $17 \mathrm{~h}$, conviver apenas com pessoas do mesmo sexo e locomover-se em fila indiana, entre outras. A partir dessa lógica, a disciplina não é de modo algum "norteadora do sucesso pedagógico", mas sim um instrumento que visa a manter cristalizada a forma de gerenciar a própria instituição, além de normalizar os jovens segundo um modelo de comportamento preconcebido. Tal modelo é o do interno bem comportado, já que o contexto disciplinar se constitui exatamente como mero "[...] instrumento de manutenção da ordem institucional" (BRASIL, 2006, p. 72).

Para o leitor compreender nossas análises, cabe salientar o conceito de racismo de Estado (FOUCAULT, 2005). Esse conceito é um termo apresentado e explicado por Foucault (2005) em 1976, mais especificamente na última aula do curso no Collége de France, transcrito em livro intitulado Em Defesa da Sociedade. Logo após evidenciar o processo de transição do poder soberano para a biopolítica estatal - ou seja, saindo de um poder que incidia na positividade da morte e passando para a positividade da vida, como apresentaremos adiante -, Foucault (2005) questiona se há certa incongruência nessa mudança de atuação do poder, o que é expresso por ele nas seguintes indagações:

[...] é possível, para um poder político, matar, reclamar a morte, pedir a morte, mandar matar, dar a ordem de matar, expor à morte não só seus inimigos mas mesmo seus próprios cidadãos? Como esse poder que tem essencialmente o objetivo de fazer viver pode deixar morrer? Como exercer o poder da morte, $[. .$.$] num sistema político centrado no bio-$ poder? (FOUCAULT, 2005, p. 303-304).

A partir dessas colocações, entendemos, então, que a prática disciplinar instituída na UNEI opera como um mecanismo de racismo de Estado (FOUCAULT, 2005); isto é, visa segregar uma parcela da população para que esta seja constantemente mantida sob uma condição tal que possa ser, não incluída para ser integrada ou socializada como parte da sociedade, constantemente posta sob uma 
vigilância para que não se misture com os demais e, mais do que isso, exposta a condições que em vez de promover a vida dessa população, promovem a sua própria morte.

Para avançarmos nessa discussão, outro conceito torna-se pertinente: a biopolítica, segundo Foucault (2005), é uma tecnologia que surge juntamente com o advento da população. É especialmente pela emergência dos Estados Nacionais que essa nova tecnologia passa a ganhar fôlego, uma vez que o investimento na vida da população passa a ser uma forma de aumentar e enriquecer a força do próprio Estado (FOUCAULT, 2005). Cabe destacar a transformação no modo de governar a partir da constituição do Estado, em detrimento do rei soberano: o poder soberano é sintetizado por Foucault como sendo de "fazer morrer e deixar viver", ao passo que na biopolítica a lógica se inverte, sendo o alvo agora a implementação de técnicas de "fazer viver e deixar morrer", fomentando a vida da população (FOUCAULT, 2005); enquanto o primeiro mostrava sua força por meio da assunção da morte, o segundo a demonstra pela assunção da vida da população.

A biopolítica reside, assim, em técnicas e estratégias que incidem com o intuito de estimular e de aumentar a vida; como exemplo de tais técnicas, podemos citar todas as campanhas de vacinação que começaram na Europa; no caso do Brasil, no início do século XX, podemos mencionar todos os modelos de higienização das cidades, saneamento, controle de epidemias, etc. Cabe enfatizar que devemos entender esse objeto da biopolítica - a população - como um conjunto de vidas humanas constantemente ameaçadas pelo processo de morbidade, sendo que o objetivo da biopolítica é atuar de modo a reduzir os processos que enfraquecem a vida dessa população, como a mortalidade infantil, as doenças endêmicas, os acidentes, as anomalias, a degenerescência, etc. (FOUCAULT, 1988).

Ao falarmos em aumentar a vida de uma população, logo nos vem a impressão de que a biopolítica é algo que visa estritamente ao bem-estar das pessoas. Contudo, entendemos com Foucault (1988) que o desenvolvimento da biopolítica também resulta em um exercício de poder que demanda um conhecimento aprofundado da população, considerando, portanto, a necessidade de seu esquadrinhamento, já que ela é um misto de diversidade de vidas; para melhor governá-las, precisa-se segmentá-las em subtipos: crianças, idosos, mulheres, trabalhadores, doentes, ricos, miseráveis, etc. Dentre esses segmentos, podemos destacar, então, os jovens em conflito com a lei.

Neste momento, salientamos que, durante a pesquisa em questão, assistimos a algumas audiências. Parece importante destacar um acontecimento que se deu no contexto de uma delas. Trata-se de um jovem que estava na audiência para a apuração de ato infracional, acusado de posse de drogas, e foi interpelado pelo juiz com a seguinte pergunta: "você é viciado em maconha?". O jovem respondeu apenas usar a droga nos momentos em que não conseguia dormir; o juiz, então, perguntou "mas por que você não consegue dormir?", e o jovem relatou ter insônia devido a conflitos familiares. Ao ouvir a resposta do jovem, o promotor começou a proferir um discurso moral a respeito do uso de drogas e do quanto elas fazem mal à saúde. Nesse momento, o jovem disse que "maconha não é droga", e o juiz interferiu, interrompendo antes que o promotor começasse com outro discurso. O juiz fez suas considerações e aplicou uma medida socioeducativa de prestação de serviços à comunidade. Quando o jovem deixou a sala, o promotor exaltou-se com a medida "branda" tomada pelo juiz e apresentou seu posicionamento sobre o caso: "eu acho que o Estado deveria internar os viciados em hospitais até eles perderem o vício".

Podemos afirmar que essa história está permeada por uma racionalidade biopolítica. Em primeiro lugar, pode-se dizer que o pano de fundo do discurso para a proibição das drogas consiste nos danos que elas causam à saúde da população, além dos riscos relacionados à criminalidade e à violência que os usuários e traficantes representam à população "normal", produtiva e sadia. Em segundo lugar, é preciso notar que esse projeto imaginado pelo promotor já está em pleno vigor no Brasil e se chama "internação compulsória". Trata-se de uma técnica biopolítica que vem se afirmando como um suposto método para salvaguardar a saúde de uma população de dependentes químicos, mas que, a nosso ver, reedita o modelo manicomial, produzindo a segregação daqueles que devem ser internados e funcionando, ao mesmo tempo, como um dispositivo de segurança, já que tira de circulação sujeitos tomados como perigosos (REIS, 2012).

Tal dispositivo biopolítico tem demonstrado que a interdição não é apenas uma forma de cuidar da saúde e da vida de uma população de dependentes químicos, mas também uma estratégia disciplinar e punitiva, porque ambas incidem simultaneamente sobre o corpo do sujeito, principalmente quando diz respeito a medidas socioeducativas de internação. De modo geral, um dos objetivos dos mecanismos de restrição de liberdade é promover o isolamento do indivíduo marginal, retirando-o do convívio com a população sadia. Nesse processo, justifica-se sua remoção para inseri-lo em instituições com finalidade terapêutica ou socioeducativa/punitiva. No caso das comunidades terapêuticas, que também são utilizadas como espaços de cumprimento de medida socioeducativa eventualmente (SCISLESKI; MARASCHIN; SILVA, 2008), os tratamentos baseiam-se em princípios de moralização religiosa dos internos. Esse procedimento moral diz respeito ao crescente número desse tipo de instituições de internação para dependentes geridas por religiosos; em grande parte, não contam com a presença de pessoal qualificado para oferecer um atendimento terapêutico (CONSELHO FEDERAL DE PSICOLOGIA, 2011).

No entanto, em alguns casos, há também algumas comunidades terapêuticas que atuam por meio do tratamento com medicamentos psicotrópicos, visando tanto à contenção da agressividade do sujeitos quanto ao combate das crises de abstinência e ao auxílio na desintoxicação. É nesse sentido que Scisleski (2010) apresenta uma pesquisa que aborda a medicalização dos jovens em conflito com a lei no contexto do Rio Grande do Sul, levantando a hipótese de a medicalização ser mais uma estratégia punitiva do que de tratamento terapêutico propriamente dito, especialmente quando o diagnóstico vem 
acompanhado de um delito (ato infracional) ou do comportamento de risco do sujeito (uso de drogas). Assim, "a medicação, além de individualizar completamente a questão do delito, permite fazer dele uma patologia, propondo como a solução do problema o remédio" (SCISLESKI, 2010, p. 87). Segundo a autora, tal lógica permite eximir a sociedade da responsabilidade pela produção de uma população marginalizada, pois, da forma como o problema é abordado - residindo nos corpos dos sujeitos -, o Estado e a sociedade nada poderiam fazer além de uma intervenção pautada pela internação/medicalização. Nesse contexto, percebemos, ainda no século XXI, uma postura biopolítica com abordagem higienista, em que todos os problemas residem no corpo "anormal" doente e a questão social quase sempre é deixada em segundo plano. Nesse aspecto, torna-se importante evidenciar que espaços como as UNEIS se impõem, a nosso ver, como um local que funciona na lógica do racismo de Estado, uma vez que a população ali internada é tratada como foco da marginalidade, percebida como "inimigos internos" que devem ser combatidos e do qual a sociedade deve ser permanentemente defendida (FOUCAULT, 2005).

\section{Relacionando racismo de Estado e tanatopolítica: a sexualidade na UNEI}

Para falar da relação da sexualidade e das técnicas de produção de morte, é preciso retomarmos a visita à UNEI. Ao chegarmos naquele local, estávamos entre quatro pesquisadores, sendo um homem e três mulheres. Na ocasião, o inspetor passou-nos alguns esclarecimentos, dizendo que nos levaria ao local onde os adolescentes estavam, porém fez a ressalva de que uma das pesquisadoras não poderia ir. Quando ela questionou o motivo, o inspetor respondeu que o problema era a blusa que ela vestia; segundo ele, "o decote era grande demais". No entanto, a roupa não nos parecia inadequada à ocasião; até aquele momento, a pesquisadora não tinha sido impedida de assistir às audiências no fórum com tal vestimenta, por exemplo. O inspetor continuou relatando que os jovens tinham uma "sexualidade aflorada" e que, por isso, poderiam sentir-se estimulados com a roupa da pesquisadora, o que a levou a seguir as orientações do referido funcionário.

No decorrer da visita, o inspetor relatou que aqueles jovens eram sujeitos com dificuldade de controlar seus impulsos sexuais. Tal afirmação nos faz questionar: se a pesquisa fosse em uma escola, e não em uma UNEI, por exemplo, as recomendações seriam as mesmas? Podemos supor, a partir da percepção do inspetor, um desdobramento para o modo como o Estado e a sociedade tomam esses jovens; ou seja, como sujeitos que não apenas têm a "sexualidade aflorada", podendo vir a ofender visitantes, mas também como indivíduos que podem vir a manifestar outros comportamentos inadequados. Nessa lógica, o jovem em conflito com a lei é compreendido como um sujeito com potencial para emitir comportamentos ofensivos.

A questão da sexualidade, apontada pelo inspetor, levou-nos a perguntar-lhe se aqueles jovens recebiam algum acompanhamento de orientação sexual, ao que ele nos respondeu que não, informando que a institui- ção tinha conhecimento de jovens portadores de doenças sexualmente transmissíveis, mas que não havia tomado nenhuma medida para evitar que os demais fossem expostos à contaminação e tampouco para impedir que os que já possuíam um tipo de patologia acabassem por desenvolver uma comorbidade, agravando ainda mais seus problemas de saúde. Diante desse cenário, percebemos que o Estado deliberadamente expõe à morte alguns de seus tutelados como estratégia governamental de fazer morrer uns para que outros vivam melhor. Nesse caso, encontramos uma aproximação com o conceito de racismo de Estado de Foucault (2005) e com o de tanatopolítica de Agamben (2007), como veremos adiante.

Ressaltamos, porém, que essa situação da sexualidade e da exposição ao risco de morte precisa ser enfatizada, pois um dos parâmetros da ação socioeducativa evidenciados pelo SINASE (BRASIL, 2006) trata exatamente da questão da sexualidade dos adolescentes. Tal texto defende que as instituições socioeducativas devem:

[...] oferecer grupos de promoção de saúde incluindo temas relacionados à sexualidade e direitos sexuais, prevenção de DST/Aids, uso de álcool e outras drogas, orientando o adolescente, encaminhando-o e apoiando-o, sempre que necessário, para o serviço básico de atenção a saúde (BRASIL, 2006, p. 71).

Novamente, nesse local, verificamos que o que impera sobre essa população é uma política de racismo de Estado. No entanto, dentro desse contexto de inclusão e exclusão, seria interessante aproximarmos essa ideia da teoria agambeniana, que diz respeito à tanatopolítica, uma vez que esta, diferentemente do racismo de Estado, trabalha com o princípio da exceção para com a vida nua; isto é, uma vida abandonada e exposta à morte.

Segundo o filósofo Giorgio Agamben (2007), a vida nua, ou zoé, foi incluída no ordenamento político-jurídico para depois ser excluída pelo princípio da exceção soberana. $\mathrm{O}$ autor italiano resgata a ideia grega de zoé, que é um termo extraído principalmente da obra de Aristóteles. A zoé pode ser definida como sendo a vida natural, de todos os seres vivos, não concernente à vida enquadrada nos requisitos da bios, já que a bios se refere à vida qualificada do cidadão grego. A zoé tem como exemplo a vida da mulher, do escravo, do meteco, das crianças, enfim, daqueles que não participam das decisões na polis.

A zoé, para Agamben (2007), em um sentido mais geral, implica a vida de um ser humano desconectada de qualquer adjetivo, ou seja, destituída de significado, uma vida reconhecida apenas pela sua anatomia-fisiologia humana, uma vida nua. Esse termo essencial chamado de vida nua por vezes aparecerá na obra do autor como sinônimo de zoé, mas não o tempo todo. Há uma diferença notável entre a zoé da Grécia antiga e a da Modernidade, como destacado por Scisleski e Guareschi (2011), que entendem que, apesar de o ingresso da zoé na polis já ter ocorrido antes da Modernidade, através da figura do homo sacer, é na Modernidade que as práticas de inserção da zoé na polis tomarão proporções muito maiores, já que evidenciam uma inclusão que se dá a partir de uma situa- 
ção de exclusão (SCISLESKI; GUARESCHI, 2011, p. 92). A ênfase da inclusão da zoé na política significa que agora ela fará parte dos cálculos do poder. Dessa forma, a biopolítica incidirá sobre essa vida a fim de protegê-la ou, inversamente, de limitá-la e ceifar sua existência, como é o caso da tanatopolítica para Agamben (2007) ou do racismo de Estado para Foucault (2005).

Cabe destacar aqui, sucintamente, o que Agamben entende por homo sacer. Essa figura tem origem na Roma antiga e diz respeito ao homem que não pode ter a vida ofertada aos deuses em sacrifício e que, se for morto, quem o matará não será culpado por homicídio. O homo sacer é um indivíduo cuja vida não tem valor nem para os deuses, nem para os homens; trata-se de uma vida que, além de ser juridicamente desprotegida, tem essa desproteção proclamada (AGAMBEN, 2007).

No caso dos jovens em conflito com a lei em questão - sujeitos que, devido à forma como são tratados, se aproximam dos critérios de definição de vida nua de Agamben (2007) -, podemos afirmar que eles são, em termos jurídicos, tomados como sujeitos de direitos no ECA (BRASIL, 1990) e nas diretrizes do SINASE (BRASIL, 2006). Quanto a isso, destacamos, inclusive, que existem políticas públicas voltadas especificamente para essa população, que são estratégias de inclusão. No entanto, quando analisamos com maior cautela como os princípios da Proteção Integral que o ECA preconiza são aplicados, o que enxergamos é a exceção como lógica de governo; isto é, o não-cumprimento desses princípios, demonstrando que a lei, em vez de proteger, abandona esses sujeitos. Essa exceção, que por vezes entendemos como "falha da norma" ou como burocracia - como é o caso da dificuldade de abertura de concursos para contratação de profissionais, acesso à prevenção de doenças sexualmente transmissíveis, melhorias das instalações locais e mesmo a não-implementação do próprio ECA, que teoricamente está em vigor há mais de vinte anos -, torna-se frequente no cotidiano do tratamento dos jovens em conflito com a lei.

Nessa relação, pode-se dizer que os direitos dos jovens estão garantidos em lei, mas é exatamente a negação de tais direitos que configura a exceção. Não devemos pensar essa situação apenas como efeito da inépcia das autoridades e do Estado em cumprir o que a lei garante, mas como produtora de algo desejado como operador de gestão. Nesse sentido, a ideia de Agamben sobre essa tanatopolítica da vida nua aponta para a seguinte conclusão: o Estado tem interesse em que esses jovens em conflito com a lei, bem como outras parcelas marginalizadas da sociedade, se configurem como vida nua e permaneçam em situação de abandono, expostos à morte. Nessa perspectiva, podemos afirmar que o que está vigorando é uma estratégia de governo não mais centrada na política, muito menos na biopolítica - que envolveria estratégias para fomentar a vida da população -, mas sim na tanatopolítica, ou seja, o que ocorre é uma produção de morte (SCISLESKI, 2010; WAISELFISZ, 2011).

Fractal, Rev. Psicol., v. 28 - n. 1, p. 84-93, 2016
Podemos discutir essa questão retomando as ideias de Foucault (1988), especialmente no que tange à sexualidade. Para o filósofo francês, a sexualidade tornou-se o ponto de intersecção entre a disciplina e a regulamentação biopolítica, sendo considerada, entre os séculos XVIII e XIX, o eixo gerador de conexão entre indivíduo, raça e população. É através dela que conseguimos compreender de forma clara a disciplina e regulamentação biopolítica atuando. Nas palavras do autor:

[...] a sexualidade, enquanto comportamento exatamente corporal depende de um controle disciplinar, individualizante, em forma de vigilância permanente [...] e depois, por outro lado, a sexualidade se insere e adquire efeito, por seus efeitos procriadores, em processos biológicos amplos que concernem não mais ao corpo do indivíduo, mas a esse elemento, a essa unidade múltipla constituída pela população (FOUCAULT, 2005, p. 300).

Segundo Foucault (1988), foi nos séculos XVIII e XIX que os estudos de hereditariedade colocaram o sexo como uma das principais causas de transmissão e geração de patologias que poderiam colocar em risco a saúde da população presente e futura. A "eugenia" e o que o filósofo chama de "medicina das perversões", especialmente composta pela psiquiatria e psicologia, podem ser consideradas como as duas grandes inovações técnicas do saber médico da segunda metade do século XIX. Dessa forma, as tecnologias eugênicas encontraram um solo fértil na teoria das degenerecências, justamente pela explicação da existência da relação entre as patologias orgânicas e as perversões. Por exemplo, um parente com uma patologia física justificava a manifestação do comportamento perverso em um descendente, assim como aquele que tivesse um comportamento perverso ou anormal também acabaria por transmitir patologias a seus descendentes.

O comportamento perverso diz respeito a todas as práticas, sexuais ou comportamentais, que iam contra a moral da época; grande parte delas eram as sexuais de cunho não-reprodutivo, como a masturbação, a sodomia, a libertinagem, etc. Muitos desses comportamentos tidos como perversos eram atribuídos às classes pobres, e o higienismo sempre se esforçou para ligar a perversão à pobreza:

O higienismo, aliado aos ideais eugênicos e à teoria da degenerescência de Morel, concebe que os vícios e as virtudes são, em grande parte, originários dos ascendentes. Afirma que aqueles advindos de "boas famílias" teriam naturalmente pendores para a virtude. Ao contrário, aqueles que traziam "má herança", leia-se os pobres, seriam portadores de degenerescências (COIMBRA, 2001, p. 90).

Apesar de Foucault (1988) ter como base de pesquisa principal o continente europeu, isso não nos impede de encontrar a repercussão dessas formas racistas de medicina e ciência no Brasil, como podemos ver no trabalho de Cecília Coimbra (2001). A referida autora expõe que no Brasil, entre o final do século XIX e decorrer do XX, o higienismo foi amplamente difundido entre as classes abastadas, e especialistas de diferentes áreas adotaram esse saber da ciência, que serviu como base tanto para ordenar as cidades quanto para tratar os pobres e marginais. 
Esse movimento, formado por muitos psiquiatras da elite brasileira da época, atinge seu apogeu na década de 1920, quando da criação da "Liga Brasileira de Higiene Mental", por Gustavo Riedel. Suas bases estão nas teorias racistas, no darwinismo social e na eugenia, pregando o aperfeiçoamento da raça e colocando-se abertamente contra negros e mestiços - a maior parte da população pobre brasileira (COIMBRA, 2001, p. 88).

Para Foucault (1988), na Europa, a transferência das técnicas de sexualização criadas dentro da e para a burguesia pôde ser difundida, ou melhor, ser implantada obrigatoriamente nas classes mais pobres, mas esse movimento não fora uma atitude caritativa da burguesia para com os menos favorecidos, para que a raça destes também se "aprimorasse". Os motivos da sexualização dos pobres e, em especial, do proletário era outro - as epidemias nas classes inferiores afetavam os burgueses pela proximidade urbana. Somam-se a isso as mudanças nas indústrias, que passaram a necessitar de mão de obra mais qualificada, que já não podia mais ser considerada como descartável:

A burguesia não se interessa pelos loucos, mas pelo poder; não se interessa pela sexualidade infantil, mas pelo sistema de poder que a controla; a burguesia não se importa absolutamente com os delinquentes nem com sua punição ou reinserção social, que não têm muita importância do ponto de vista econômico, mas se interessa pelo conjunto de mecanismos que controlam, seguem, punem e reformam o delinquente (FOUCAULT, 1979, p. 174).

Foucault (1988), no livro História da sexualidade I: a vontade de saber, resume a sexualização em três etapas sucessivas: a primeira diz respeito à natalidade; a segunda, à família; e a terceira, ao desenvolvimento de tecnologias médico-jurídicas. No século XVIII, tinha-se a consciência de que nação forte era nação populosa, então, passou-se a valorizar a natalidade e a combater qualquer método contraceptivo. $\mathrm{O}$ segundo aspecto dizia respeito à canonização da família e à moralização dos mais pobres. O terceiro concernia ao desenvolvimento das instâncias médico-jurídicas no final do século XIX, que passaram a exercer pleno controle sobre a sexualidade da população em nome da preservação e do melhoramento da raça da população. Essas técnicas médicas um tanto "tautológicas" ganharam poder de atuação sobre a população, conferido pelo aparato estatal, cada vez mais inclinado a tratar a vida como uma inteligibilidade puramente biológica. Assim, em favor de uma política racista, surgem técnicas que proporcionam o que Foucault (2005) chama de racismo de Estado, como já explicado anteriormente.

As ideias de Foucault (2005) levam-nos a concluir que é tão somente por meio do racismo de Estado que a morte será incluída na biopolítica ou dentro dos cálculos dessa modalidade de biopoder, ou seja, racismo de Estado é a forma primordial de articulação entre o "fazer viver e o deixar morrer" em uma realidade biopolítica. Tal racismo produz morte, mas não uma morte como uma demonstração de força - como no caso do poder soberano -, e sim como um meio de fortalecimento da vida e da raça de uma população; esse racismo atua com o princípio de que, para se viver ou para aumentar a força da vida enquanto raça, é preciso uma operação de morte que mate ou exponha à morte. Aqui, vemos uma aproximação entre o conceito de tanatopolítica de Agamben (2007), abordado anteriormente.

\section{Problematizando a matança dos jovens no Brasil: a contribuição do pensamento de Foucault e Agamben}

É interessante, neste momento, aproximar um pouco os estudos de Foucault a respeito da ideia de racismo também aos da autora Hannah Arendt (2011), no livro Origens do totalitarismo. Nele, a autora aborda o desenvolvimento do racismo europeu, argumentando a respeito do uso do racismo como arma política e ideológica do imperialismo:

Desde o início do século XX, o racismo reforçou a ideologia da política imperialista. $\mathrm{O}$ racismo absorveu e reviveu todos os antigos pensamentos racistas, que, no entanto, por si mesmos, dificilmente teriam sido capazes de transformar o racismo em ideologia (ARENDT, 2011, p. 188).

O que Foucault (2005) e Arendt (2011) nos mostram é que o racismo não foi e não é apenas uma opinião impensada e inconsequente de alguns ignorantes. Com esses autores, compreendemos que o racismo foi e, em alguns casos, ainda é usado tanto como base para o desenvolvimento científico e biopolítico, quanto como justificativa para políticas que visam ao lucro através da exploração e extermínio de povos considerados pertencentes a uma raça inferior ou possuidores de uma cultura desprezível. No século XX, o racismo foi a base lógica para a legitimação do imperialismo europeu em outras partes do mundo: matanças na China, na Índia e principalmente na África só conseguiam justificação por um ponto de vista racista: "Exterminemos todos esses brutos!". Dessa ideia, resultaram os mais terríveis massacres da história: "[...] e o que é pior, a adoção desses métodos de 'pacificação' pela política externa europeia comum e respeitável” (ARENDT, 2011, p. 215).

$\mathrm{O}$ racismo de Estado não impera somente nos grandes acontecimentos históricos. No Brasil, perceberemos o racismo de Estado de forma cotidiana. Como já explicitado em alguns trechos deste texto, nós o encontramos no tratamento desumano aplicado a detentos e jovens presos e internados, na exposição a riscos e também em vários casos de chacinas de moradores de rua, de crianças abandonadas e jovens pobres da periferia, além do genocídio histórico/atual das populações indígenas.

Em nosso século XXI, as nações do ocidente dizem repudiar, pelo menos conceitualmente, essa forma aberta e legalizada de regulação da vida a partir da concepção de raças, talvez para afugentar o fantasma do nazismo. Entretanto, a nosso ver, isso não significa que essa prática está em desuso, mas que apenas se ocultou, não exigindo mais amparo científico e legal para funcionar. As práticas de morte de cunho racista simplesmente deixaram de exigir legitimação formal para operar na vida da população e, assim, passaram a funcionar de forma definitiva no campo da exceção (AGAMBEN, 2004).

Fractal, Rev. Psicol., v. 28 - n. 1, p. 84-93, 2016 
Retomamos, então, esse jogo entre a vida e a morte no campo da gestão das formas de vida da população a partir das concepções de racismo de Estado em Foucault (2005) e de tanatopolítica de Agamben (2007). Podemos dizer que tanto a tanatopolítica quanto o racismo de Estado têm como método para gerir a população a produção de morte, seja pela exposição a riscos, seja por abandono, eutanásia ou extermínio propriamente dito. Entretanto, as conclusões de Agamben (2007) remetem-nos a um nível mais íntimo das relações do poder com a capacidade de interditar a vida. Foucault (2005) explica que os sujeitos se relacionam com o racismo de Estado tão somente enquanto membros de uma raça ou população. Na tanatopolítica, essa relação manifesta-se entre aqueles que são identificados como vida nua e os que se prestam ao papel de soberanos (AGAMBEN, 2007).

Enquanto Foucault (2005) aponta o racismo de Estado como sendo mais um instrumento biopolítico que visa a fortalecer a raça ou a população produtiva, a tanatopolítica de Agamben $(2004,2007)$ mostra como a morte pode ser legitimada sem que tenha de passar por um movimento de legalização - essa constatação aponta a forma pela qual a morte é gerida no nosso século através da exceção.

Para salientar como esses processos se apresentam na realidade brasileira, podemos citar alguns dados estatísticos provenientes do Mapa da Violência (WAISELFISZ, 2011) que mostram um processo de extermínio (homicídios) relacionado a um tipo racial distinto: o jovem negro. Segundo esse estudo, no Brasil, no ano de 2010, foram vítimas de homicídio 13.668 brancos e 33.264 negros, o que significa que "morrem proporcionalmente $139 \%$ mais negros que brancos; isto é, bem acima do dobro!" (WAISELFISZ, 2011, p. 62), sendo que, dentre os negros, "pertenciam ao sexo masculino 91,4\%" (WAISELFISZ, 2011, p. 66). O estudo apresenta também uma indagação sobre a ausência de políticas públicas voltadas para a redução das práticas de extermínio da população juvenil negra, indicando que a tendência das últimas décadas tem sido a redução da morte de brancos e o aumento da de negros, sem qualquer remissão no índice total de homicídios. Entretanto, podemos afirmar não só que a mortalidade de jovens negros no nosso país não é apenas fruto de processos históricos anteriores, mas também que ela coloca em evidência uma lógica atual e expansiva de um racismo de Estado nutrido por uma sociedade que não se livrou realmente do pensamento racista dos séculos anteriores.

Como se pode explicar a matança de seres humanos que necessariamente não representam nem risco físico nem biológico à população sadia? Agamben (2007) lembra que muitas das vidas interditadas na biopolítica moderna não são seres humanos que poderiam ser identificados como potenciais riscos à sociedade (risco biológico, econômico, moral ou social) e que sua manutenção não acarretaria encargos para o Estado a que elas pertencem. Pelo contrário, por vezes, é mais custoso para o Estado organizar um esquema de extermínio desses indivíduos do que simplesmente deixá-los à espera da morte natural.

Fractal, Rev. Psicol., v. 28 - n. 1, p. 84-93, 2016
Por isso o autor cita o programa de eutanásia criado pelo Estado nazista, situação que nos leva a reconhecer que o racismo de Estado, em alguns casos, se torna insuficiente.

Mas de um ponto de vista estritamente eugenético, a eutanásia não era particularmente necessária: não somente as leis de prevenção das doenças hereditárias e sobre a proteção da saúde hereditária do povo alemão representavam já uma tutela suficiente, mas os doentes incuráveis submetidos ao programa, em grande parte crianças e velhos, não tinham em todo caso condições de reproduzir-se (AGAMBEN, 2007, p. 148).

A ideia de Agamben (2007) consiste em que os Estados Nacionais - no caso do exemplo, o Estado Nazista - passam a transformar parcelas de suas populações em seres matáveis. Essa possibilidade de transmutar uma vida protegida pelo direito em uma vida matável resulta na constituição de um poder incalculável, posto que as possibilidades em manipular a vida nua são irrestritas. Essa vida nua pode ser aprisionada em condições desumanas, ser torturada e explorada, pode servir de cobaia para experimentos, seus órgãos podem ser retirados, e sua existência pode ser destruída. Enfim, o corpo do homo sacer moderno é um campo sem limites da aplicação de um "tanatopoder": "separar em um outro homem a zoé do bíos e de isolar nele algo como uma vida nua, uma vida matável. Mas, na perspectiva da biopolítica moderna, [...] isso assinala o ponto em que a biopolítica converte-se necessariamente em tanatopolítica" (AGAMBEN, 2007, p. 149).

O soberano, para Agamben (2007), inspirado no pensamento de Carl Schmitt, é aquele que decide tanto sobre o estado de exceção quanto sobre a vida que será abandonada. A vida cuja proteção do direito será suspensa relaciona-se ao que Agamben entende por bando, como vidas abandonadas, fora da proteção jurídica, expostas à morte. É na relação do soberano com esse ser abandonado pelas instâncias jurídico-políticas, esse homo sacer, que a tanatopolítica se constituirá. Podemos entender que, nessa lógica, os soberanos da atualidade não são mais os herdeiros de um território com o poder de tirar a vida de seus súditos, mas sim todo homem que consegue atuar na produção de morte ou desumanização de outro ser humano sem ser responsabilizado por isso.

Agamben (2007), ao falar dos experimentos realizados por conceituados médicos e cientistas nas $V P-V e r-$ suchepersonen -, isto é, cobaias humanas nos campos nazistas, e das similares experiências com condenados em prisões norte-americanas (AGAMBEN, 2007), por exemplo, faz referência, de certo modo, à experiência do suplício. A leitura das descrição de tais experiências, realizadas no século XX, principalmente durante a Segunda Guerra Mundial, causa-nos um mal-estar tão significativo quanto o provocado pelos conhecidos suplícios praticados na Idade Média, quando grande parte dessas experiências terminava com a morte da cobaia humana.

Ao analisar esses acontecimentos, Agamben (2007) conclui que isso só foi possível graças ao estado de vida nua a que esses sujeitos eram reduzidos. $\mathrm{O}$ autor afirma: "o que aqui nos interessa especialmente, porém, é que no horizonte biopolítico que caracteriza a modernidade, 
o médico e o cientista movem-se naquela terra de ninguém onde, outrora, somente o soberano podia penetrar" (AGAMBEN, 2007, p. 166).

Não é difícil identificar a atuação desses "soberanos" nos tempos atuais. Retomemos nossa experiência de pesquisa com os jovens em conflito com a lei. $\mathrm{Na}$ terceira audiência à que assistimos, durante o depoimento de um jovem acusado, o juiz indagou-lhe: "o que você tem feito da vida?". Essa questão, à luz dos estudos realizados, permite-nos analisar que a vida não é algo inerente à existência do sujeito, mas algo que lhe foi dado. Subsequentemente, o juiz fez uma segunda indagação ao jovem a respeito dos estudos e ainda uma terceira pergunta para saber da ocupação do interrogado: "você trabalha?". As respostas do jovem para as duas primeiras perguntas foram confusas e falhas, mas, na terceira questão, ele respondeu com firmeza: "sim, eu trabalho". O juiz mostrou-se satisfeito com a resposta, porém seguiu perguntando: "em quê?". O jovem respondeu: "como auxiliar de pedreiro", e o magistrado observou: "é bom que você está tomando jeito". É importante salientar que o referido jovem não tinha mais de dezesseis anos e que em nenhum momento o juiz lhe perguntou se o empregador pagava os encargos trabalhistas. Acreditamos que a ausência desse questionamento remete ao entendimento de que, por tratar-se de um jovem infrator, o importante é que este se ocupe, seja produtivo, ainda que seus direitos trabalhistas não sejam respeitados.

A partir da situação explanada, pode-se entender como a exceção soberana atua, pois, se a vida desses jovens pobres é incluída através de uma legislação que lhes garante direitos e deveres, a incapacidade do Estado para a ação - ou, pelo contrário, muita capacidade para a exceção - de atender a esses mesmos direitos coloca-os em situação de abandono. No entanto, quando os jovens não cumprem os seus deveres - não-cumprimento esse que muitas vezes é decorrente da própria "falha" na garantia dos direitos -, tais como estudar, ser disciplinado, não cometer atos infracionais, entre outros elementos, percebe-se que a mesma legislação incapaz de atender a seus direitos os intercepta, obrigando-os a encontrar-se com aqueles que representam os soberanos de nossos tempos: o policial, o pedagogo, o psicólogo, o médico, o juiz, etc. Dessa maneira, esses jovens são expostos à morte - entendendo aqui morte não apenas como a extinção da vida biológica estrita, mas como a desqualificação dessa vida, através do acesso a bens culturais, educação e família, entre outros -, como é o caso da situação de interná-los em locais que ameaçam sua saúde por riscos de contaminação, violência, etc. Não é incomum o magistrado favorecer, ou consentir, a entrada de jovens em um mercado de trabalho que os inclui no sistema produtivo da sociedade, mas que também os exclui dos direitos trabalhistas, ao mesmo tempo em que os expõe à morte (SCISLESKI, 2010; REIS, 2012). É nesse sentido que tomamos essas relações como que pautadas por uma lógica de racismo de Estado (FOUCAULT, 2005) e de tanatopolítica (AGAMBEN, 2007).

\section{Considerações Finais}

Diante desse cenário geral, delineado a partir das práticas dirigidas aos jovens em conflito com a lei, percebemos que as formas para governar essa população, apesar das garantias proclamadas pelo ECA, evidenciam, ao mesmo tempo, as dimensões das próprias violações dos direitos desses jovens. Se, por um lado, o ECA trouxe avanços significativos à população juvenil em geral, por outro, vemos que, quando se trata de jovens em conflito com a lei, por vezes a legislação não vigora, fazendo com que muitos desses jovens continuem vivendo em uma situação de marginalidade social. A complexidade da questão aponta para a necessidade de pensarmos os efeitos dessas práticas que promovem uma cisão no corpo dessa população: políticas que governam para a vida, mas que também governam para a morte quando permitem a não-implementação e a violação dos direitos desses sujeitos.

\section{Referências}

AGAMBEN, G. Estado de exceção. Tradução de Iraci D. Poleti. Belo Horizonte: UFMG, 2004.

AGAMBEN, G. Homo sacer: o poder soberano e a vida nua. Tradução de Henrique Burigo. Belo Horizonte: UFMG, 2007. v. 1.

ARENDT, H. Origens do totalitarismo. Tradução de Roberto Raposo. 9. ed. São Paulo: Companhia das Letras, 2011.

BRASIL. Presidência da República. Casa Civil. Subchefia para Assuntos Jurídicos. Lei $n^{\circ}$ 8.069, de 13 de julho de 1990. Dispõe sobre o Estatuto da Criança e do Adolescente e dá outras providências. Disponível em: $<$ http://www.planalto.gov. br/ccivil_03/LEIS/L8069.htm>. Acesso em: 21 abr. 2013.

BRASIL. Presidência da República. Secretaria Especial dos Direitos Humanos. Conselho Nacional dos Direitos da Criança e do Adolescente. Sistema Nacional de Atendimento Socioeducativo - SINASE. Brasília: CONANDA. 2006. Disponível em: <http://www.conselhodacrianca.al.gov.br/salade-imprensa/publicacoes/sinase.pdf $>$. Acesso em: 21 abr. 2013.

BRASIL. Senado Federal. Proposta de Emenda à Constituição $n^{\circ} 33$, de 2012. Altera a redação dos arts. 129 e 228 da Constituição Federal, acrescentando um parágrafo único para prever a possibilidade de desconsideração da inimputabilidade penal de maiores de dezesseis anos e menores de dezoito anos por lei complementar. 2012. Disponível em: <http://www25. senado.leg.br/web/atividade/materias/-/materia/106330>. Acesso em: 13 jun. 2013.

COIMBRA, C. B. Operação Rio: o mito das classes perigosas. Niterói/Rio de Janeiro: Intertexto, 2001.

COIMBRA, C. B.; NASCIMENTO, M. L. do. O efeito Foucault: desnaturalizando verdades, superando dicotomias. Psicologia: Teoria e Pesquisa, Brasília, v. 17, n. 3, p. 245-248, set.-dez. 2001

CONSELHO FEDERAL DE PSICOLOGIA. Comissão Nacional de Direitos Humanos. Relatório da $4^{a}$ Inspeção Nacional de Direitos Humanos: locais de internação para usuários de drogas. 2. ed. Brasília: Conselho Federal de Psicologia, 2011. Disponível em: <http://site.cfp.org.br/ 
wp-content/uploads/2012/03/2a_Edixo_relatorio inspecao VERSxO_FINAL.pdf>. Acesso em: 12 mar. 2012.

CUNHA, J. R. F. A lanterna de Diógenes: considerações sobre a justiça na Justiça. In: BRITO, L. M. T. de (Org.). Jovens em conflito com a lei. 2. ed. Rio de Janeiro: Eduerj, 2000. p. 49-62.

FOUCAULT, M. Microfisica do poder. Rio de Janeiro, Graal, 1979.

FOUCAULT, M. História da sexualidade: a vontade de saber. Tradução de Guilhon de Albuquerque. 13. ed. Rio de Janeiro: Graal, 1988. v. 1, p 152.

FOUCAULT, M. Vigiar e punir: o nascimento da prisão. Tradução de Raquel Ramalhete. 20. ed. Rio de Janeiro: Vozes, 1999.

FOUCAULT, M. Em defesa da sociedade: curso no Collége de France (1975-1976). Tradução de Maria Ermantina de Almeida Prado Galvão. 2. ed. São Paulo: Martins Fontes, 2005.

LIMA, T.; MIOTO, R.; PRA, K. D. A documentação no cotidiano da intervenção dos assistentes sociais: algumas considerações acerca do diário de campo. Revista Textos \& Contextos, [S.1.], v. 6, n. 1, p. 93-104, 2007.

MATO GROSSO DO SUL. Fundação do Trabalho de Mato Grosso do Sul. Relatório da pesquisa do perfil socioeconômico dos jovens internos das UNEIS de MS. Campo Grande: Observatório do Trabalho de Mato Grosso do Sul/Funtrab, 2012.

MATO GROSSO DO SUL. OAB/MS. Comissão Permanente de Direitos Humanos. Relatório da visita in loco a Unidade Educacional de Internação (UNEI) Dom Bosco. Campo Grande: OAB, 2014.

REIS, C. dos. (Falência Familiar) $+($ Uso de Drogas $)=$ Risco e Periculosidade: a naturalização jurídica e psicológica de jovens com medida de internação compulsória. 2012. 132 f. Dissertação (Mestrado em Psicologia Social e Institucional)Programa de Pós-Graduação em Psicologia Social e Institucional, Universidade Federal do Rio Grande do Sul,Porto Alegre, 2012.

SCISLESKI, A. C. C. Governando vidas matáveis: as relações entre a saúde e a justiça dirigidas a adolescentes em conflito com a lei. 2010. 108 f. Tese (Doutorado em Psicologia)-Programa de Pós-Graduação em Psicologia, Pontifícia Universidade Católica do Rio Grande do Sul, Porto Alegre, 2010.

SCISLESKI, A. C. C.; GUARESCHI, N. M. F. Pensando o governo: produzindo políticas de vida e de extermínio. Athenea digital, [S.1.], v. 11, n. 2, p. 85-99, 2011.

SCISLESKI, A. C. C.; MARASCHIN, C.; SILVA, R. N. da. Manicômio em circuito: o percurso dos jovens pelas redes sociais e a internação psiquiátrica. Cadernos de Saúde Pública, [S.1.], v. 24, n. 2, p. 342-352, fev. 2008.

WAISELFISZ, J. J. Mapa da violência 2012: os novos padrões da violência homicida no Brasil. São Paulo: Instituto Sangari, 2011. Disponível em: <http://www.mapadaviolencia.org.br/ pdf2012/mapa2012_web.pdf>. Acesso em: 21 abr. 2013.

Recebido em: 2 de julho de 2013

Aceito em: 4 de junho de 2015 